\title{
Influence of flatness distortion of free-form surface in a fitting process
}

\author{
Wpływ odchyłki płaskości powierzchni swobodnej \\ na dopasowanie w procesie montażu
}

\section{ANNA ZAWADA-TOMKIEWICZ DARIUSZ TOMKIEWICZ *}

DOI: https://doi.org/10.17814/mechanik.2017.11.176

\begin{abstract}
The main objective of the study was to present a study of flatness deviation in the context of the possibility of matching 2 tempered glass panes in the lamination process. The paper presents an example of an analysis of the fit that provides total interchangeability and partial interchangeability.

KEYWORDS: thermally toughened soda lime silicate safety glass, overall bow, roller wave distortion, edge lift
\end{abstract}

Laminated safety glass is produced by the connection of tempered glass with filler layer [1, 2]. The requirement for flat tempered glass in the joining process is that the flatness deviation is within the set tolerance. In this way, we can talk about complete interchangeability - glass panes, regardless of the layout, will always be matched, and the space between them will be filled with an intermediate layer. If the tolerance is too high, it forms a volume of the intermediate layer that will not be able to fill when combined with another sheet of glass. In this view, partial interchangeability can be said - only in the arrangement of the mutual glass pane, the space between them will be filled by the intermediate layer.

The aim of the study was to analyze the effect of surface flatness deviations - which are generated during the heat treatment of flat glass - on the mutual matching of the surface in the process of bonding the safety laminated glass (ISO 12543-1 and ISO 12543-2).

\section{Flatness surface deformation}

In the course of heat treatment, the change of material properties occurs - its resistance to mechanical and thermal loads is increased and a specific fragmentation characteristic is imparted to it. Material properties change causes distortions (fig. 1). In the process of horizontal tempering of glass, the periodic distortion resulting from the movement of heated glass on rolls becomes significant. The standard EN 12150-1 divides the form of distortion into two groups: overall bow $(\mathrm{OB})$ and roller wave $(\mathrm{RW})$ as well as edge lift $(\mathrm{EL})[3,4]$.

\footnotetext{
* Prof. nadzw. dr hab. inż. Anna Zawada-Tomkiewicz (anna.zawada-tomkiewicz@tu.koszalin.pl), prof. nadzw. dr hab. inż. Dariusz Tomkiewicz (dariusz.tomkiewicz@tu.koszalin.pl)-Politechnika Koszalińska
}

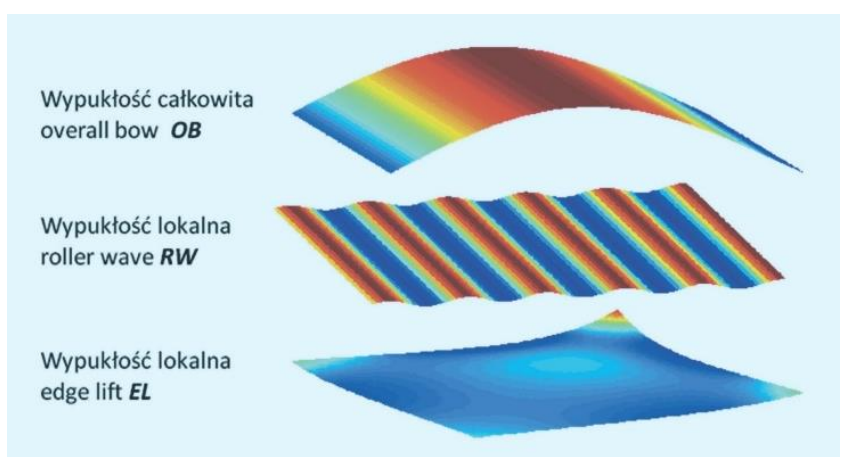

Fig. 1. Types of flatness deviations of tempered glass panes in a horizontal process

\section{Matching with complete interchangeability}

In the case of a horizontal hardening process, intensive heating and cooling of the glass pane results in three main types of overlapping distortions [5]:

- overall bow (deformation of the entire pan of tempered glass),

- roller wave (distortion caused by the contact of the glass pane with rotating rolls during hardening),

- edge lift (front and rear distortion of the glass edge).

Recommendations on measurement and limit values of the total protrusions are included in the EN 12150-1.

Deviation is measured as the maximum distance between the flat reference surface and the concave surface of the glass pane. The overall bow value is expressed as deviation value, in millimeters, divided by the measured glass edge length or diagonal.

Overall bow has the greatest effect on matching two glass panes. If both panes are so flat that they do not exceed tolerances, the average distance between them will vary from 0 to $4 \mathrm{~mm}$, taking into account the shape of the empty volume. Simulations of the minimum mean distance between two glass panes were determined taking into account the volume error and the minimum thickness of the intermediate layer to be used to fill the empty volume. In the worst case, when both surfaces form a convex space, the volume of empty space is the maximum. The least favorable fit of the tempered glass panes of the tolerances of the overall bow must be reduced to half the permissible value defined in standard [3]. 
Roller wave distortion is defined as the difference between maximum and minimum local deviation of the glass sheet at a length of $300 \mathrm{~mm}$. The most favorable situation is when the roller wave is coherent (similar amplitude and phase for the given frequency). Inconsistency in one parameter makes the local deviations add up. Simulations of fitting two glass panes with a roller wave of a permissible value indicate that, in the worst case, the mean value of the distance between the glass panes does not exceed $1 \mathrm{~mm}$.

The edge lift is measured as the maximum distance between the front and end edges of the glass pane and the reference surface at a length of $300 \mathrm{~mm}$. The edge lift deviation has no significant effect on the overall bow distortion in volume terms. On the other hand, there may be 2 cases of glass panes. The first, preferred case, is one, in which the edges of the glass adhere to each other and form a closed space without delaminating at the edge. Much less advantageous is the situation when the edges of the match spread. In this case, the behavior of permissible deviation value does not guarantee filling the empty volume at the edges. In order to avoid delamination of the laminated glass on the edges, the admissible edge lift deviation should be limited to the thickness of the intermediate layer.

\section{Fitting with partial interchangeability - selective match}

Any 2 sheets of glass obtained from production, with deviation values within the defined tolerance, may be adversely matched and delamination or non-filling of the volume with the intermediate layer will occur during the joining process. If it is not possible to narrow the tolerance limits, the only solution is the selective match. It is based on the fact that each pane of glass can have 4 different orientations in relation to the other pane and there are as many as 16 different possibilities of matching 2 specific pieces.

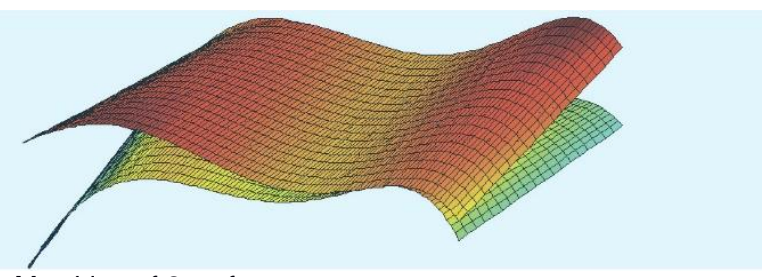

Fig. 2. Matching of 2 surfaces

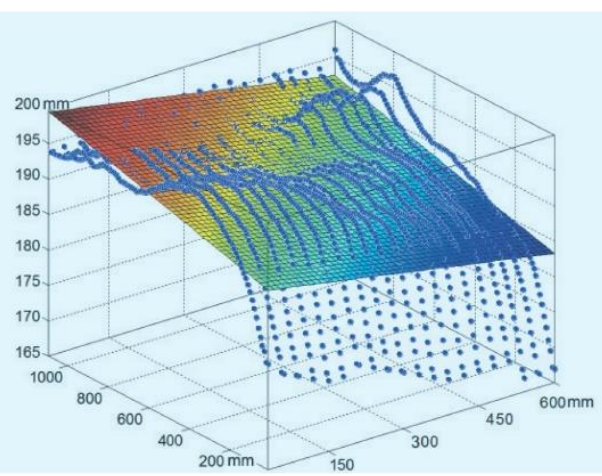

Fig. 3. Determination of flatness deviations of tempered glass sheet

In order to effectively match 2 surfaces with certain flatness distortions, the distribution of these distortions over the entire surface must first be determined. A machine vision inspection system was developed which, without interfering with the technological process, was able to measure the whole glass pane and then determine the distribution of deviations in 3D.

Measurements were first used to check whether the deviations were within tolerable limits. The analyzed parameters included the overall bow OB, roller wave RW and edge lift EL. Next, a free surface model was created for each of the glass panes and a surface match was made so that the minimum distance between them was 0 with support at 3 points ( 1 translation operation and 2 rotation operations). For the matched model surfaces, the mean distance in millimeters was determined. This can be interpreted as the average thickness of the intermediate layer required to fill the volume between the glass panes.

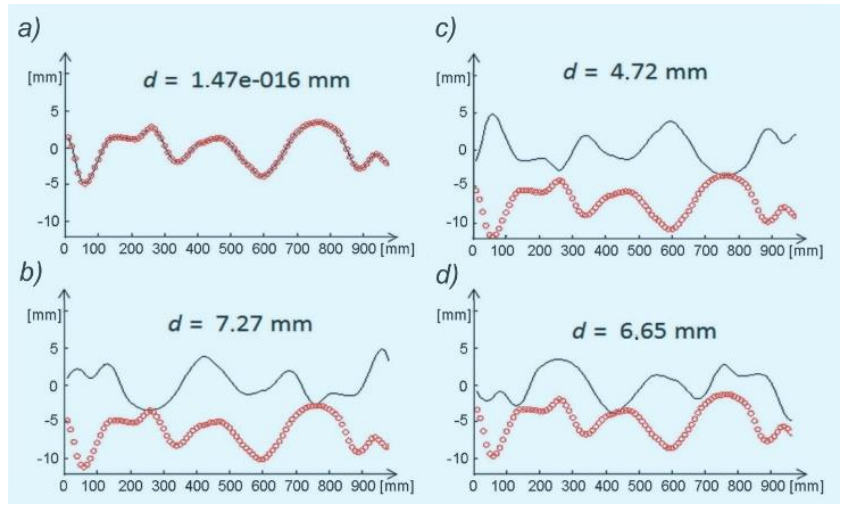

Fig. 4. Maximum distances between two tempered glass panes along the direction of maximum deviations

As can be seen in fig. $4 a$, when deviations of two glass panes are consistent in 3D space, the match is nearly perfect. Other cases show situations, in which 2 surfaces are not well matched. This means that although 2 glass panes are almost identical, when the distortion does not overlap in the 3D space, empty voids with mean thickness greater than the thickness of the intermediate layer (figs. $4 b-d$ ) are formed. An analysis of $3 \mathrm{D}$ deviation distribution for each tempered glass panes makes it possible to select one of 16 reciprocal settings optimally, or to find that the laminated glass cannot be properly assembled.

\section{Conclusions}

The effect of flatness deviation in the tempered glass panes on the quality of match in the laminated glass process was analyzed. The possibility of matching with total and partial interchangeability was examined. In the case of total interchangeability, the effect of the flatness deviation type and its permissible value on the matching process was analyzed. In the case of partial interchangeability, the matching analysis was based on the measurement system developed by the authors.

\section{REFERENCES}

1. ISO 12543-1:2011 Glass in building. Laminated glass and laminated safety glass -- Part 1: Definitions and description of component parts

2. ISO 12543-2:2011 Glass in building. Laminated glass and laminated safety glass -- Part 2: Laminated safety glass

3. EN 12150-1: 2015 Glass in buildings - Thermally toughened soda lime silicate safety glass - Definition and description.

4. EN 12150-2: 2004 Glass in building. Thermally toughened soda lime silicate safety glass $\square$ Evaluation of conformity/Product standard.

5. GGF Datasheet for the Quality of Thermally Toughened Soda Lime Silicate Safety Glass for Building (www.ionglass.co.uk). 